\title{
The Song of the Science Mermaid: A Philosophical Trilogue on the Osteological Paradox
}

\author{
Alessandra Morrone \\ Department of Archaeology \\ Institute of History and Archaeology \\ University of Tartu \\ Jakobi 2 \\ Tartu 51005, Estonia \\ Email: alessandra.morrone@ut.ee
}

\section{Lisa Zorzato}

Department of Philosophy

Institute of Philosophy and Semiotics

University of Tartu

Jakobi 2

Tartu 51005, Estonia

Email: lisa.zrz@gmail.com

\begin{abstract}
As a modern academic Ulysses, the historical scientist is enticed by numerous plausible scientific theories that can explain the historical data in search of the truth. However, the predicament of her work is to inevitably crash onto the rocks and cliffs of uncertainty. The problem discussed in this paper is that several scientific models can be suitable to account for the same empirical observations. The risk of falling into speculation is looming, and exceedingly dangerous in science. This is also the case in archaeological sciences, such as bioarchaeology. A bioarchaeologist frequently encounters traces of disease in ancient skeletons, and pertinent patterns may often result from equally probable different causes. This is a methodological issue commonly encountered in the interpretation of pathological patterns in human remains, and constitutes part of the problem known in bioarchaeology as the osteological paradox. During an informal trilogue, three characters discuss the osteological paradox, and attempt to define it in philosophical terms. The aim of this work is to present the problems of scientists with the philosophical
\end{abstract}


approach to the debate between scientific realism and antirealism, focusing in particular on the so-called problem of underdetermination. Our original approach is to apply the distinction between 'how-possibly' models and 'how-actually' models by Alisa Bokulich to archaeological issues, integrating various fields of science with a multidisciplinary and omnivorous approach. The trilogue ends providing the historical scientist with reasons and means to believe in her ability to conceive of true and reliable scientific models to interpret the historical past.

Keywords: bioarchaeology, osteological paradox, paleopathology, philosophy of science, physical anthropology, realism vs. antirealism

\section{Introduction}

The characters of this brief trilogue are three PhD students and researchers. Two of them are philosophers, while the third is a bioarchaeologist. After a long and difficult working day, among papers, professors, students and bones, they decide to meet up for drinks. On this occasion, they open up and talk about their research problems. The trilogue continues until late evening, integrating the philosophical debate between realism and antirealism with several practical examples that are frequently encountered in bioarchaeology. The conclusion of this discussion, accounting for the views of the philosophers and the historical scientists, highlights the importance of adopting a multidisciplinary and omnivorous approach while attempting to explain the past.

\section{Setting}

It's 3.00 pm. Café in the beautiful city centre in Tartu. It is a chilly and sunny day in mid-February and the smooth snow in the streets shines and glitters in the sun. The place is warm and cosy, with a diffuse and intense scent of coffee. People are talking in the background, and the lights are soft and warm. Three girls are sitting at a round table, enjoying a cup of black coffee. 


\section{Characters}

Alessandra: bioarchaeologist. She deals with paleopathology, which is the study of disease in the past. Her job is to analyse the disease patterns detectable in skeletal remains from ancient populations.

Lisa: realist philosopher. Her study concerns what is science, its methods and its aims. She advocates the view that scientific theories are true descriptions of reality.

Ariel: antirealist philosopher. Her study concerns what is science, its methods and its aims. She advocates the view that scientific theories are useful instruments without any truth claims.

In Chapter I, starting from a specific bioarchaeological case study, the philosophical problem of underdetermination is brought to bear on the osteological paradox, a theoretical issue frequently encountered by bioarchaeologists during the investigation of ancient human remains. Chapters II and III are dedicated to the philosophical debate between realism and antirealism, applied to bioarchaeological contexts. In the final Chapter IV, the summary of the whole discussion and conclusions are presented.

\section{A trilogue Chapter I}

The scientist hears the mermaid's song. The problem: several scientific models can account for the same empirical observations.

Lisa: "Good afternoon! This second year of doctoral research is rather intense. How are your studies progressing?”

Alessandra: "Lisa, I agree with you about this year! I am currently working on a particularly interesting case, focused on a group of newborns discovered in a medieval cemetery here, in the city centre. This mass burial of babies was most likely connected to episodes of famine and epidemic recorded in the historical sources of the time. I have thoroughly studied their skeletal lesions but, unfortunately, I encountered some issues in their interpretation. I realised that their disease patterns can be explained by several medical diagnoses. (Morrone et al., 2021)" 
Lisa: "Oh, I didn't think you could have similar problems in your field. May I ask you why are there so many possible diagnoses? Aren't the lesions directly and unambiguously correlated with a specific disease?"

Alessandra: "Unfortunately, they are not. Let me explain how a paleopathologist works. When investigating ancient diseases, a specific procedure known as differential diagnosis is adopted. This comprises a set of practical and diagnostic steps. The first is a thorough and detailed description of the lesions and their location, adopting standard terminology and using internationally recognised guidelines (Roberts \& Connell, 2004; Steckel et al., 2005). The second step is to include this set of lesions into a pattern (if and when possible), and to identify a list of possible causative agents compatible with the observed lesions, using the medical and paleopathological literature available. The third step is the most challenging, since the researcher has to critically rule out the less probable causes one by one, eventually reaching the correct aetiology (if very lucky), or at least proposing a list of most likely causative agents (Ortner, 2003). The diagnostic process is a complex critical effort, in which not only medical and epidemiological data, but also historical, environmental, archaeological and biomolecular sources are carefully taken into account.

Returning to my case study, I can provide you with an example linked to a specific lesion: I have found abundant porosity in the long bones of several newborns in my sample. According to previous case studies and current paleopathological literature, this bone porosity may be ascribed to many different aetiologies: it can be the result of systemic metabolic conditions such as scurvy, anaemia and rickets, as well as a standard consequence of the normal rapid growth of newborns (Lewis, 2007; 2018)."

Ariel: "Let me understand better: would it be as if I entered my car, turned the key, and realised that it could not start? I would have no idea which was the cause of this problem until I investigated it better."

Alessandra: "Exactly. The causes for the car not starting can be various and all plausible: it could be due to the fuel supply, or to the battery conditions, or to an electronic problem. The same issue occurs when I analyse abnormal bone porosity in my sample: how do I know which were the diseases effectively affecting these babies if the resulting lesions appear so similar? I would like to be able to pick the right aetiology and causal explanation for the observed bone changes in light of the historical context, but this appears to be impossible. How would you define my problem in philosophical terms?" 
Ariel: "The situation that you sketched is defined in philosophy of science as the problem of underdetermination. Let me quote the book by Adrian Currie I am reading these days: 'underdetermination occurs when evidence cannot decide between two competing hypotheses' (Currie, 2018 p. 265). The main principle is that there are alternative theoretical understandings that are empirically equivalent with our scientific theories. In your case, you can develop several different theories or models to explain the abnormal porosity on your individuals, but it is unlikely that you will provide a true reconstruction of the pathological conditions affecting them at that time, as well as the numerous other additional factors influencing their life and death. Historical scientists cannot regard their scientific theories as leading to true beliefs. If you are seeking support in believing that you are effectively reconstructing historical truth, unfortunately it will not come from me."

Lisa: "Ariel is right. In the philosophy of science debate, your problem is vividly discussed. The problem of underdetermination is one of the main arguments advanced in support of the antirealist position. The link between this principle and antirealism is that different alternative theories about the same data inevitably lead to agnosticism towards the claim for one true theory. For a realist, it is indeed irrational not to believe that our science is driving us to a true understanding of the world."

Alessandra: "This argumentation is really interesting, especially when applied to my field of research. However, I am not very practical with philosophical discussions. What is the basis of the debate between scientific realism and antirealism?"

Lisa: "Historically, the debate has become pressingly relevant in relation to unobservable entities (such as electrons). Epistemic philosophical questions arose: are unobservables posed by our scientific theories real? Can we believe in those entities? Or is it better to consider the theories about them only as tools to make predictions and not as truth-conducive? Those questions frequently overlap with metaphysical and semantic fields, as well as with philosophy of language. More generally, the debate has always been present in science, and its 'coordinate positions are defined by the axes of reality, truth, and knowledge' (Niiniluoto, 1999). Questions concerning the justifiability of our beliefs, the progress of science, and the notion of scientific truth are all addressed. For our conversation, we do not need to go deep in the explanation of what is truth: I consider as true those theories that are accurately describing external reality, so that there is a correspondence between the statements of a theory and the phenomena in the world. 
In the recent debate, the definition of scientific realism has multiple variants, but the core claims are (1) that scientific theories describe the phenomena in the world, and (2) that the progress of science is, step by step, approximating a true understanding of reality. I think the definition by Chakravartty (2011) has been, so far, widely accepted by philosophers: 'scientific realism is a positive epistemic attitude towards the content of our best theories and models, recommending belief in both observables and unobservable aspects of the world described by sciences'. Note that a realist is not claiming that a scientific theory is finally true and not open to revision, but rather that the progress of science is possible as a continuous redefinition and development of theories. The main argument for the realist is the so-called no miracles argument that sounds as follows: how is it possible for our best scientific theories to be so successful in making empirical predictions if they are not, at least partially or approximately, true? It would be an incredible coincidence, a miracle, for a false theory to predict the right phenomena (a canonical reading for this argument is Psillos, 1999). As an empirical support, realists claim that theories are corroborated by different experimental evidence with the advance of new technology and methodology. The reality of an electron is then supported by the fact that it is detected by our apparatus, and it would be clearly a miracle if our theory about it were completely wrong but still so successful.

As a rule, the antirealist stands on the opposite side of that. The space for different arguments is huge. Typically, the antirealist claims that there is no motivation for believing in the truth of our scientific theories, in particular about the postulated unobservable entities. This claim can lead to a strong scepticism or to a more moderate position, called instrumentalism, according to which theories merely 'save the phenomena', i.e., are useful and adequate tools without any commitment to truth. Two are the main arguments for antirealism: the underdetermination of theory by data and the pessimistic meta-induction. According to the former, since there are radically different alternatives that can explain the same phenomena, it is pointless to believe in the truth of a scientific theory. According to the latter, history has shown that science is unreliable ontologically and semantically, since it has been continuously disconfirmed.

These philosophical reflections concern not only 'hard sciences', but also the so-called 'soft sciences': the different framework of space and time of the archaeological data opens the door to the realism debate (for an overview, see Salmon, 1993). As Peter Kosso (2001) claims, scientific entities may be considered unobservable for a number of reasons: they may be either too small (such as 
atoms, bacteria, or molecules), or too distant (such as astronomical objects). They might also be located in the past, which is what specifically undermines Alessandra's research. Due to the decay of the historical traces naturally occurring with time, the amount of information that archaeologists collect is always incomplete and the data is always unobservable. It is then likely that different alternative interpretations of the same observational data may emerge, leading again to the notorious dilemma: are our scientific theories true or not?"

Ariel: "Considering the case of Alessandra, I stress that, since there are different alternative theories that can explain the same bone changes, the problem of underdetermination is clearly present in scientific investigation. How can we be sure that the one endorsed by scientists is the true one? Your case illustrates in practice that the knowledge we can achieve is far from a description of reality, and that we should be agnostic towards the claim that we can achieve true knowledge about the world."

\section{Lisa takes a sip of her black coffee.}

Lisa: "Ariel, your mermaid name is emblematic of your mindset. It really looks like you are assigning to the scientific theories referred to by Alessandra the role of Ulysses' Sirens: the song of the science mermaid is mesmerising and irresistible for the historical scientist, but it will inevitably lead her to doom and damnation, for her research for truth will be fatal. Just as it happens with the irresistible call of the Sirens, this temptation is uncontrollable by the scientist, at least partially. A critical approach generally prevails, but the inner need to 'trust' a scientific theory in order not to feel out of track is sometimes evident, and in many cases leads one to conclusions that are way too simplistic or even completely speculative. This may happen in good faith but, unfortunately, also in bad faith."

Alessandra: "This sounds like an epistemological epic! In fact, my problem is much more similar to the scenario Ariel has proposed. In my case study from Tartu explained above, unfortunately the abnormal porosity looks exactly the same in newborns, whatever the cause (Morrone et al., 2021).

In other luckier situations, some patterns of bone lesions are strongly indicative of specific pathological processes, and are known in paleopathology as pathognomonic for a specific disease. A well-known example of a pathognomonic pattern is represented by the set of skeletal lesions connected to human tuberculosis. In the advanced stages of this chronic and devastating disease, Mycobacterium 
tuberculosis (one of the several bacterial species belonging to the genus Mycobacterium, which also includes leprosy) can pass from the primary infection in the lungs to the bloodstream, eventually migrating to other anatomical areas such as muscles and bones (Roberts \& Buikstra, 2003). Once the bacteria have reached the skeleton, the generated lesions are always of a destructive nature; the areas more commonly affected are the vertebral bodies, as well as the hip bones and the proximal ends of the femurs (Aufderheide \& Rodríguez-Martín, 1998; Ortner, 2003; Roberts \& Buikstra, 2003). The infection results in numerous abscesses that progressively destroy the bone tissue, frequently causing fractures and the final collapse of the skeletal area under the individual's weight. The most typical pattern can be observed in the vertebral column, in which the collapse of the infected vertebral bodies creates a characteristic anterior kyphosis in the lumbar area, known as Pott's disease (Aufderheide \& Rodríguez-Martín, 1998; Ortner, 2003; Roberts \& Buikstra, 2003). Similar pathognomonic patterns effectively allow obtaining prevalence data for this disease: since you have found Pott's disease, it is highly likely that you are dealing with skeletal tuberculosis, and therefore you can calculate the prevalence of diseased individuals in the population for paleodemographic purposes.

However, in most cases these kinds of lesions are detected alone, and not in the context of a specific pathognomonic pattern. Hence, you will not have the luxury of obtaining the prevalence data for a specific aetiology, and you are somehow forced to draft a list of possible causes. It must be also considered that the identification of particular pathological patterns in an archaeological specimen may be greatly hindered by the preservation conditions of the skeleton. The taphonomic effects of soil, water, plant roots, animal scavenging and human activities are all destructive agents that contribute to the loss of information from your specimen (Baxter, 2004). Hence, perhaps the analysed skeleton did effectively show a pathognomonic pattern of lesions, but you might be able to find just a few traces of the original set of changes, or no trace at all.

The problems listed above frequently lead the researcher to the necessary development of several paleodemographic models in order to explain a particular pathological pattern; these models may all reconstruct the past in a reasonable way.

In paleopathology and paleoepidemiology, this problem is covered by some of the principles of the osteological paradox. The term, which is slightly improper in its philosophical meaning but has been extensively used in the bioarchaeological field, was introduced in a seminal paper published by James Wood, George Milner, Henry Harpending and Kenneth Weiss in 1992 in the 
journal Current Anthropology. It was the result of a particularly active line of research in paleodemography (see reviews by Wright \& Yoder, 2003; Siek, 2013 and DeWitte \& Stojanowski, 2015). This milestone gave rise to issues for a vivid debate that is still ongoing almost 30 years later (and is far from being completely solved). The basis of these issues is that no skeletal sample is fully representative of the living population from which it was gathered. As a result, different (and often mutually exclusive) paleodemographic models may all fit the recorded disease patterns, and may all represent plausible reconstructions of the pathological profile of the population. This leads to great limitations in making inferences about the health of the living communities based on the frequency of skeletal diseases, and most of our final interpretations might be irremediably biased (Waldron, 1994; Ortner, 2011).

Wood et al. (1992) described three essential problems encountered by researchers attempting to reconstruct the paleodemography of ancient populations using data from archaeological human remains: (1) hidden heterogeneity in frailty, i.e., individuals are unequal in their vulnerability to disease and stressors due to a combination of intrinsic factors, and therefore often vary in their individual risks of death (DeWitte \& Stojanowski, 2015). This also implies that not everyone at the same risk of exposure may show signs of a particular disease, and who does may also display different levels of severity in the developed lesions. Everyone eventually dies, but not all individuals of a given age experience the same risk of death at that particular point in their life. Each age group in mortality samples is enriched by the diseased and injured, or by those who engaged in particularly hazardous jobs or lifestyles (Milner \& Boldsen, 2017); (2) selective mortality, i.e., the prevalent data for particular pathologies are gathered from cemetery samples that are already irremediably biased representatives of past populations, just for the fact of being dead! These individuals automatically represent the highest risk of death in the population at a given age, and therefore the abundance of their lesions is unrepresentative of the conditions of the living population at any given time (DeWitte \& Stojanowski, 2015).

These two concepts are deeply intertwined with one another, and can be easily explained with a typical example that is frequently used in the field: you have found a well-preserved skeleton showing no visible signs of any known disease, therefore appearing 'perfectly healthy'. This individual may have effectively been completely healthy, perhaps passing away due to an accident or soft tissue injury. On the other hand, this person may have suffered from an acute disease causing his/her rapid death (such as typhus, dysentery or plague, which frequently 
followed periods of famine or warfare in antiquity), without having enough time to develop stress markers for the causative pathogen. This second interpretation would therefore identify this person as one of the frailest individuals in the population, and definitely not a healthy specimen. If either of these interpretations is applied to the entire cemetery population, you can easily understand how the whole demographic profile will change significantly according to the adopted model. Similar scenarios are quite common in bioarchaeological studies, as those who died from acute diseases associated with famine or epidemic are very likely to appear 'healthy' in the skeletal record. ${ }^{1}$ Returning to the abovementioned example of tuberculosis, you have probably noticed that I have used the term skeletal tuberculosis. This clarification is mandatory, as it indicates that we are only sure about the prevalence of those individuals showing pathognomonic signs on the skeleton. In the absence of further evidence (that is, relying solely on macroscopic observations), we are inevitably forced to record the chronic, and are unable to infer anything about the acute.

In their paper, Wood et al. (1992) propose a hypothetical scenario involving a population constituted of three subgroups, each with the same probability of contracting a disease that is potentially deadly, and produces distinctive skeletal lesions (think of tuberculosis). Subgroup (A) never contracts the disease, therefore does not develop skeletal lesions. Subgroup (B) contracts the disease, and this lasts long enough to allow developing skeletal changes, but few to no deaths occur. Subgroup (C) also experiences the disease, but in these individuals it progresses much more acutely than in Subgroups (A) and (B), causing their rapid death before any skeletal signs are developed. So in the end, only one of these subgroups effectively displays recognisable skeletal changes. As a result, both subgroups (A) and (C) are assumed to consist of one healthy subgroup, while (B) is defined as unhealthy (Wood et al., 1992). Therefore, it becomes clear that the osteological paradox in similar cases may lead to overlooking or misinterpreting the occurrence of an ancient disease, sometimes underestimating the prevalence of particular pathologies, assumed to be rare or nonexistent (Siek, 2013).

The third point is purely statistical, and is represented by (3) demographic nonstationarity, meaning that cemetery assemblages might be derived from populations that experienced migration or temporal changes in fertility and

1 Note that the concept of osteological paradox here is not generated by a mere 'healthy/unhealthy' verbal dichotomy, but rather results from the lack of empirical evidence for the specific causative agents. Therefore, several explanations become potentially suitable to explain past health conditions. 
mortality. Therefore, if the age groups are not equally distributed (as it occurs in the great majority of our samples), a population bias may occur. This point is less concerned with our philosophical discussion.

The issues described above greatly complicate the study of demographic patterns and disease in past populations. In particular, they hinder any inference about health and mortality directly from measurements such as the mean age-at-death, life expectancy, or prevalence of pathological lesions estimated from skeletal assemblages (DeWitte \& Stojanowski, 2015). Furthermore, they result in the articulation of a plethora of explanatory models for a specific scenario. My case study of newborns represents a typical example of this glitch.

Is the osteological paradox solvable? The answer is no, it cannot be avoided nor completely solved. However, it can be at least minimised. In order to overcome and partially downplay the effects of the osteological paradox, Wood et al. (1992) strongly recommended a multidisciplinary approach to the study of health and disease, always keeping in mind the importance of historical records and contextual information. In particular, they suggested the need for research on the underlying causes of heterogeneity in frailty in modern populations from a physiological and medical point of view, to be associated with a demographic research on how frailty is related to risk of death (Wood et al., 1992; Wright \& Yoder, 2003). Similar aspects are dealt with by several biological sciences, and go way beyond the reach of bioarchaeology alone (Wright $\&$ Yoder, 2003; Reitsema \& McIlvaine, 2014; DeWitte \& Stojanowski, 2015). The authors indeed stressed that with regard to these topics 'the osteologists are unlikely to make fundamental contributions, and must remain consumers rather than producers of the relevant theory and observations' (Wood et al., 1992). However, they later indicated a final important task in which the bioarchaeologist does have an active role, such as the investigation and better understanding of the historical and cultural contexts from which the material is driven (Wood et al., 1992). Exploring the role of culture in generating heterogeneity in frailty and its interactions with selective mortality is one of the main powers of a bioarchaeologist, and ought to be the starting point for any proper historical reconstruction (Wright \& Yoder, 2003). The comments provided by several eminent figures in the anthropological field, reported at the end of the paper by Wood et al. (1992), provided new directions to expand on the topic; it is generally agreed that the historical scientist would and should greatly benefit from this collaborative and 'omnivorous' approach (Siek, 2013; Reitsema \& McIlvaine, 2014; Temple \& Goodman, 2014; Milner $\&$ Boldsen, 2017; DeWitte \& Yaussy, 2020). 
Returning to the typical example of the 'healthy' skeleton, historical records and biomolecular analyses may solve this particular problem. Let us say that this individual was found in a mass grave with another fifty skeletons. And let us also say that radiocarbon dating placed him/her in the mid-14th century, and that local written sources reported an extreme loss of human lives due to the spread of the Black Death in that region. This would produce a more nuanced set of evidence, ruling out some incorrect hypotheses and providing a plausible explanation for the absence of skeletal changes in this particular specimen, as well as in other individuals from the same context. Regarding the tuberculosis example, which represents another case of osteological paradox when limited to the mere macroscopic examination, we can affirm that the progress in the study of ancient DNA in the last twenty years finally allowed us to detect the presence of Mycobacterium tuberculosis also in individuals without any skeletal signs of disease (Donoghue, 2017). Therefore, it can be assumed that what is affected by the osteological paradox in the present, may not be affected by it, or may be affected differently, in the future. So, what are your thoughts?”

\section{Chapter II}

The mermaid has seized the scientist, and is leading her deep into the realm of uncertainty. In light of underdetermination, true theories are simply not achievable by science.

Ariel: "In my opinion, your situation becomes even worse from an antirealist point of view. As Lisa said before, following the antirealist view, there are two reasons why it is hazardous to fully believe that either of your different diagnoses are correct: because the variables are way too many (that is the argument we already addressed) and because each of these theories that are accepted as true will be radically replaced by new ones. This last argument is called pessimistic meta-induction. Grounded on the concept of paradigm shifts developed by Kuhn, the antirealist claims that the success of a theory is not sufficient to justify the belief in a theory as the one capturing true features of the world. The philosopher Laudan (1981, p. 33) made a list of fundamental theories, such as the phlogiston, the caloric, the Ptolemaic theory, that have been replaced. Tracking the history of science, we should then infer that our present theories too (for example, the theory of relativity) will be proven false in the future. How do we guarantee the truthfulness of our scientific theories? The expectation of the refutation of our current explanations invalidates the realist's approach. 
All this trust in scientific progress is misplaced: think about the majority of scientific theories developed in the past: they have always been replaced, and systematically so, by other more recent scientific theories. Nothing forbids us to think that in the future current theories will not meet the same destiny. For instance, concerning your field, I was recently reading this really interesting article about Variola virus DNA in mummies. A group of scientists reconstructed the Variola virus genome from a seventeenth-century child mummy. Contrary to all that was previously theorised about the existence of Variola virus in Europe, the mummy sequence was surprisingly recent: molecular-clock analyses revealed that the timescale of smallpox evolution is way more recent than often supposed, with the diversification of major viral lineages only occurring within the 18th and 19th centuries, close to the development of modern vaccination (Duggan et al., 2016). This is a very recent example of this continuous refutation of scientific theories."

Alessandra: "This line of reasoning subtly implies that nearly all my work has been done in vain, and that my credibility as a scientist is greatly compromised. This is a very hard theoretical issue to cope with for a scientist, and this is demonstrated by the numerous critiques of the paper by Wood et al. (1992) at the time of its publication. Among the strongest reactions, Goodman (1993) harshly criticised the author's hypothetical reinterpretation of specific examples, declaring that Wood et al. (1992) 'demonstrate the dangers of scientific snobbery and present an example of a biological anthropologist that does not consider cultural contexts' (Goodman, 1993). Furthermore, Goodman (1993) claimed that the osteological paradox does not exist, since the authors focused on single rather than multiple health indicators and failed to consider other lines of evidence. He continued criticising the hypothetical examples provided, which appear way too simplistic in respect to the real experience of a historical scientist, being mathematically possible but biologically and culturally highly improbable (Goodman, 1993). A critique of Wood et al. was also proposed by Cohen et al. (1994), who revised one of their past case studies, reconsidered it under the light of the osteological paradox, and finally concluded stating that their previous interpretations were still valid, representing the most likely explanations of their archaeological data (Cohen et al., 1994).

However, the disagreements expressed in these papers should not be considered as really concerning the cautious approach to the osteological paradox and the theoretical and statistical issues brought about by counterintuitive bioarchaeological results; they are rather focused on the unrealistic and simplistic 
nature of the hypothetical models proposed, exposing a problem that is more methodological than conceptual.

Let us return to our philosophical discussion, and to the difficulty in assuming that my differential diagnoses are correct. Could I ever infer that the success of one of my paleopathological theories or models is a guarantee of its truthfulness?"

Lisa: "Maybe, but an antirealist would say that the success of your theory or model is not enough. For example, in physics, the shift from the Ptolemaic theory to the heliocentric one, or the passage from Newtonian mechanics to general relativity did not happen smoothly. There is, in the history of science, a genuine replacement of theories, and the replaced theory is simply not accepted as correct anymore. However, as I mentioned before, I (as a realist) can appeal to the no miracles argument: how to explain the spectacular empirical success of a theory without considering that it is not, at least approximately, true? For instance, how can an eclipse be predicted a long time in advance if the theory involves no real understanding of how the world works or if it is unable to grasp at least something about reality?"

Ariel: "I am really happy that you are bringing Newtonian mechanics as an example. As you know, general relativity genuinely replaced the commitment to the central claims of Newtonian gravitational theory, i.e., the fact that gravitational forces exist. Still, Newtonian models are used to predict phenomena, either concerning calculations on the scale of the solar system, or the planning of a space trip. This is clearly evidence that a false model can explain phenomena. So, the no miracles argument is not supported by evidence. In contemporary philosophy of science, this point has been extensively discussed by Bokulich (2016). She points out that a fictional model can explain phenomena: for example, the tides on the Earth are still explained by a Newtonian and not by a general relativistic model."

Lisa: "You are giving me the possibility to quote Bokulich again. In this particular case study, the fact that there is a specific case leads to a distinction which it is necessary to make here: what we'll call here 'theory' is not the same as what we'll call 'model'. The former is a coherent cluster of ideas, methods and techniques that addresses general situations covering different specific cases. Instead, the latter concerns a single specific case. There is no time now to discuss the relation between theories and models; what I want to point out here is that, according to Bokulich, some models are 'autonomous', and are what she calls 'how-possibly' models: 'how-possibly explanations are explanations that, though not known to 
be the case, do not conflict with known facts and, by having testable predictions, avoid the charge of being mere 'just-so' stories' (Bokulich, 2014).

In science, they are generally employed in exploring specific situations, in search of explanations. They are checked and their explanatory fitness is assessed in practice. When, and if, they are found to be satisfactory on the basis of standard epistemic criteria, they become 'how-actually' models considered faithful representations of the phenomenon under investigation. The more empirical confirmation we have, the closer we are to a 'how-actually' model. Moreover, Bokulich stresses that adequate attention must be paid to 'the different contexts in which an explanation can be given and the different levels of abstraction at which the explanandum phenomenon can be framed' (Bokulich, 2014).

In the case of historical sciences, where there is a collection of data without a clear theory explaining all of them, this diversification is really important. Here, for example, we have a case study based on bones, without a general theory that can explain our findings and, based on the knowledge that we have, we propose different models to explain the data. All of them are 'how-possibly' models that are advancing suggested explanations for the observed data, but none of them is established as a 'how-actually' model, because they are only exploratory at this stage. This seems to be a case of underdetermination, but not all possibilities have been tested yet. In other words, thanks to the development of scientific expertise, models that were before inconceivable are now conceived and concretised. This is what you are doing with your process of differential diagnosis: you are investigating the range of possibilities, proceeding to rule out all explanations that are not possible, eventually reaching a list of results that are plausible. So, as I said before, the case of underdetermination here does not fit, because in the future one of your different models will be confirmed, turning from a 'how-possibly' model into a 'how-actually' model. Let me say it again: all hypotheses about your case, Alessandra, are 'how-possibly' models, on whose basis the antirealist cannot appeal to the problem of underdetermination in support of the antirealist position."

Ariel: "Your argument is really interesting, but there are two questions that I cannot explain. First, referring to the 'how-possibly' explanations of Bokulich, you spoke of models that do not conflict with facts, yet are not known to be the case. Are those models fictional? If so, how would those fictional models be applied to a case in the real world, being therefore connected with a specific case as a description of reality? Again, how can you conclude that a Newtonian model is giving us a genuine explanation of reality? Furthermore, how can a 
'how-actually' model be related to reality? Remember that, as you said earlier this evening, the correspondence between reality and theory is essential for a realist."

Lisa: "Those are both good and complex questions and, in my opinion, they are the most fascinating part of Bokulich's view. In general, you are asking how is it possible to conciliate her position with realism, considering the explanatory power of fictional models. Following Bokulich (2011), fictional models can 'give us genuine insight into the way the world is. Specifically, they can do so by correctly capturing in their fictional representations, real patterns of structural dependencies in the world'. Let's reply to your first question: the point here is that a Newtonian model is able to give us precise predictions because, at some level of abstraction, it displays some structural correspondences with general relativity, the theory we accept as a faithful representation of reality. These structural correspondences are what secures the link between reality and fictional models, warranting that fictional models can indirectly grasp something about the world: fictional models are not phenomenological; rather, a fictional model can stand in as a proxy for a theory we consider truthful. As Bokulich (2016) stresses, 'the fictional mechanism is a representation or model of the true mechanism, and if it is a good one-one that captures the real structural features or patterns of counterfactual dependence- then it can (when used with due diligence) stand in for the true mechanism in the scientist's reasoning and explanations, even though the ontology of the fictional mechanism is wrong'. However, let me emphasise that 'not known to be the case' is not identical with being fictional! A fictional model is known to be a wrong portrayal of reality, just as Newtonian gravity is thought to be in light of general relativity. On the contrary, the 'how-possibly' models, appropriate for approaching the problem Alessandra is facing, are not fictional; they are hypotheses in the process of discovering true connections with reality. Therefore, the answer to your second question, how a 'how-possibly' model is related to reality, is: taking proper account of the pertinent contexts and the corresponding levels of abstraction to frame the explanandum phenomenon, as I noted above, our model is being checked in scientific practice, its 'fitness' is being assessed, and either it is discarded or is transformed into a 'how-actually' model, establishing the relation sought for. In summary, my advice for you is to be patient, since one of the hypotheses you are critically considering in your work will eventually provide you with the right explanation.” 


\section{Chapter III}

The scientist is released from the tight embrace of the mermaid and is able to break free. There are compelling reasons to argue that a scientific theory is true and that the scientist can be confident in it.

It is 6.00 pm. It is now dark outside, and large snowflakes are slowly falling in the empty streets of the city centre. The girls order a bottle of wine, enjoying their evening.

Ariel: "The problem of eliminative inference has not been completely solved yet. Stanford (2006), for instance, has explained this point rather thoroughly. In the history of science, it became clear that along with the theory that we currently consider as the best one available, there are several alternative theories that scientists are not able to conceive yet, but that will be considered true in the future. The limitations of scientists in conceiving of all possible alternative theories makes the eliminative induction strategy (which is the one that allows us to develop a scientific theory) basically impossible. According to Stanford (2006), the elaboration process of these theories will always be limited, and scientists, at any given time, will necessarily fail in conceiving important alternatives that will eventually be confirmed as the best explanation for empirical data. This is called by Stanford the problem of unconceived alternatives, and it is one of the most powerful arguments in support of the antirealist vision. (She ironically raises her wine glass). A toast?"

Alessandra: "(Ignores the toast.) So, are you implying that the effective aetiology of my abnormal porotic lesions could likely be a combination of physiological and environmental factors that I have not even imagined yet, and that I may take into consideration in the future after further research, or that I may never conceive of them at all?"

Ariel: "Precisely."

Lisa: "I have to counter-argue again. Even if Stanford's argument is considered a good point for the debate, there are different valid replies to his version of pessimistic metd-induction over the historical record. For our purposes, I will quote what I consider one of the main objections to this argument: Godfrey-Smith (2008) focused on the progress in the scientific community, and considered the current scientific community strong enough to avoid the problem of unconceived alternatives, being able to consider all of the suitable explanations of a certain phenomenon. A realist does not claim that the current theory is the complete one; rather, she is conscious of the constant challenge to science, in the complex 
process of investigation and understanding of our nature. Falsification of theories does not impair our cognitive success as our theories mature. In other words, the progress of science is made via falsifications, errors and failures. Materials and technological instruments, models, the unification of theories, the collection and analysis of data in your field are sound and precise, and assist the scientist in the elaboration of theories that become more and more detailed with time. Once you have found the ancient DNA of plague or tuberculosis, you are also able to identify your pathogen with a rather high likelihood ratio. Scientific progress in manipulating unobservable phenomena is indubitable, even for an antirealist. All technological devices are constructed on the basis of scientific theories (e.g., electromagnetism as well as quantum mechanics), showing that our knowledge of the world is improving day by day. This means that scientific progress, continuously ongoing, will turn one of your 'how-possibly' models into a 'how-actually' model. Although the realist point of view does not completely resolve your uncertainties, your model will be corroborated in the future.

Let me try to explain one more point. Let's go back to the problem of underdetermination. An antirealist would definitely suggest that Alessandra's case is an excellent example of this argument. My response is that there is no underdetermination here. Although I do not deny that there is a valuable empirical equivalence of alternative explanations for the same data, I grant that this situation is faced by scientists all the time. To repeat, the possible answers to open questions are different 'how-possibly' models, competitive alternative hypotheses that are part of the natural development of science. It may be that some of them are confirmed, some corroborated, some discarded, and some (perhaps) will be properly assessed only in the future. The underdetermination as a philosophical problem is neither relative to the attitude of scientists, nor to the methodology, or to whatever the development of science may be. It claims that, if you have a set of data, you will never be certain about a definitive one theory, out of many, accounting for those data. The point of the problem of underdetermination is a constant epistemic situation, in which the true answer is not achievable in principle. It is a fact that in archaeology, as well as in geology or other natural and historical sciences, some data is irretrievably lost. This is an empirical problem, and as a realist, I think that the antirealist, when invoking cases such as bioarchaeological studies, is mistaking the common situation relative to the current state of science (quite natural) for the epistemic limit due to an underdetermination of theory by data which is, instead, an absolute limit.

So, shall we have our toast?" 
The girls raise their glasses.

All: "Cheers!!!"

\section{Conclusion}

The trilogue comes to an end, but the epic trip is never over.

This paper has presented and discussed the issues encountered by human paleopathologists during the investigation of ancient disease patterns in archaeological human remains. The common theoretical and methodological problem constituted by the osteological paradox was described and interpreted in light of the philosophical debate between scientific realism and antirealism. The fact that different alternative models can all be plausible in explaining and reconstructing the health status of ancient communities gives the impression that archaeological issues are affected by the persisting problem known in philosophy of science as the underdetermination of theory by data.

Following Bokulich $(2011 ; 2014 ; 2016)$, our suggestion here is to make three important distinctions: the first one concerns the difference between theory and models. While a theory is addressing the generic features shared by a whole class of phenomena, a model is constructed to account for a single case. Therefore, the problems encountered by historical scientists may all be considered as involving models, since each of them constitutes a case study by itself.

The second distinction is between 'how-possibly' and 'how-actually' models. The former are mainly exploratory models that are probing the world to glean possible connections. The latter are instead closer to a truthful explanation of the physical world. The hypotheses that scientists, including historical scientists, are developing when facing new phenomena are 'how-possibly' models. The correlation between models and the world is provided by the level of abstraction involved in models that enables capturing some aspects of physical reality. The main implication of our suggestion is that the particular problems that paleopathologists are facing in their work do not represent a case of underdetermination: the choice between alternative models in reconstructing the past crucially depends on the practices of testing and validating of models. A fruitful point here is that, on the one hand, we have a clearer understanding of what the limits of the problem of underdetermination are; on the other hand, we also understand the practical difficulties of the scientist. The abundance of plausible models seeking to reconstruct the past is a natural aspect of the scientific 
procedure employed by an historical scientist, and not a bona fide philosophical problem.

The third distinction to be made is between 'how-possibly' models and the fictional models that are widely used in science. Ironically, the trilogue itself resonates with these issues: despite being fictional, it works well in generating knowledge about the mindset of scientists and philosophers facing the same problems. The validation of the great explanatory power of hypothetical models is constituted by this very fictional trilogue!

The conclusion of this reflection is not solving the debate between realists and antirealists, which will remain open. However, it has increased the trust that we have in our scientific theories and in the future validation of one of the 'howpossibly' models that an historical scientist develops to reconstruct past events, transforming it into a 'how-actually' model, the closest reconstruction of the past that a scientist can hope to achieve in that historical moment.

'How-actually' models benefit from the integration of various fields of science, which contribute to the generation of knowledge. Historical scientists are already very conscious of this fact, and constantly rely on it in their everyday work in a somehow omnivorous way. As Wood et al. (1992) also advised at the end of their article, the examination of the historical and archaeological contexts, as well as the contribution of different branches of science (such as ancient DNA studies, stable isotope analysis, human biology, epidemiology, primatology, and many others) may lead to a better understanding of the osteological data, reaching more nuanced and suitable inferences.

Finally, the modern scientist Ulysses should not shun the possibility of creating multiple alternative models to explain the past, for this does not represent the song of a science mermaid leading her to eternal failure. On the contrary, Ulysses is traveling full sail towards knowledge, driven by the winds of progress and aided by different scientific branches that contribute to a clearer unfolding of her course. Hence, we are confident in providing the historical scientist with reasons and means to believe in her ability to conceive truthful and reliable models in reconstructing the historical past. 


\section{Acknowledgements}

The authors wish to thank Riin Kôiv, Ave Mets, and Vassilis Sakellariou for their precious advice and support in the development of this work.

Our research was supported by the University of Tartu ASTRA Project PER ASPERA (European Regional Development Fund), by the grant of the Estonian Ministry of Education No. IUT20-5 and the grants of Estonian Research Council No. PRG 462 and PRG 492, and by the Personal Research Funding schemes under Grant IUT20-7, MOBERC14. The research for this article was conducted with the support from the European Regional Development Found (Dora Plus grant Action2).

\section{References}

Aufderheide, A. C. \& Rodríguez-Martín, C. (1998), The Cambridge Encyclopedia of Human Paleopathology, vol. 478, Cambridge: Cambridge University Press.

Baxter, K. (2004), 'Extrinsic factors that effect the preservation of bone', Nebraska Anthropologist, vol. 62, no. 19, pp. 38-45. Retrieved from https://digitalcommons. unl.edu/nebanthro/62 [accessed Mar 2021]

Bokulich, A. (2011), 'How scientific models can explain,' Synthese, vol. 180, no. 1, pp. 33-45. https://doi.org/10.1007/s11229-009-9565-1

Bokulich, A. (2014), 'How the tiger bush got its stripes: 'How possibly' vs. 'How actually' model explanations,' The Monist, vol. 97, no. 3, pp. 321-338. https://doi.org/10.5840/monist201497321

Bokulich, A. (2016), 'Fiction as a vehicle for truth: Moving beyond the ontic conception,' The Monist, vol. 99, no. 3, pp. 260-279. https://doi.org/10.1093/monist/onw004

Chakravartty, A. (2011), 'Scientific realism,' in E. N. Zalta (ed.) The Stanford Encyclopedia of Philosophy, Summer 2011 Edition. Retrieved from http://plato.stanford.edu/ archives/sum2011/entries/scientific-realism/ [accessed Mar 2021]

Cohen, M. N. (1994), 'The Osteological Paradox reconsidered,' Current Anthropology, vol. 35, no. 5, pp. 629-663. https://doi.org/10.1086/204323

Currie, A. (2018), Rock, Bone, and Ruin: An Optimist's Guide to the Historical Sciences, Cambridge, MA: MIT Press. https://doi.org/10.7551/mitpress/11421.001.0001

DeWitte, S. N. \& Stojanowski, C. M. (2015), 'The osteological paradox 20 years later: Past perspectives, future directions,' Journal of Archaeological Research, vol. 23, no. 4, pp. 397-450. https://doi.org/10.1007/s10814-015-9084-1 
DeWitte, S. N. \& Yaussy, S. L. (2020), 'Bioarchaeological applications of intersectionality,' in C. Cheverko, J. Prince-Buitenhuys \& M. Hubbe (eds.) Theoretical Approaches in Bioarchaeology, Abingdon: Routledge, pp. 45-58. https://doi.org/10.4324/9780429262340-4

Donoghue, H. D. (2017), 'Insights gained from ancient biomolecules into past and present tuberculosis-a personal perspective,' International Journal of Infectious Diseases, vol. 56, pp. 176-180. https://doi.org/10.1016/j.ijid.2016.11.413

Duggan, A. T.; Perdomo, M. F.; Piombino-Mascali, D.; et al. (2016), '17th century Variola virus reveals the recent history of smallpox,' Current Biology, vol. 26, no. 24, pp. 3407-3412. https://doi.org/10.1016/j.cub.2016.10.061

Godfrey-Smith, P. (2008), 'Recurrent transient underdetermination and the glass half full,' Philosophical Studies, vol. 137, no. 1, pp. 141-148. https://doi.org/10.1007/s11098-007-9172-2

Goodman, A. H. (1993), 'On the interpretation of health from skeletal remains,' Current Anthropology, vol. 34, no. 3, pp. 281-288. https://doi.org/10.1086/204170

Hacking, I. (1965), Logic of Statistical Inference, Toronto: Macmillan of Canada, Cambridge University Press. https://doi.org/10.1017/CBO9781316534960

Hempel, C. G. (1966), Philosophy of Natural Science, Oxford: Prentice-Hall.

Kosso, P. (2001), Knowing the Past: Philosophical Issues of History and Archaeology, Amherst, NY: Humanity Books.

Laudan, L. (1981), 'A confutation of convergent realism,' Philosophy of Science, vol. 48, no. 1, pp. 19-49. https://doi.org/10.1086/288975

Lewis, M. E. (2007), The Bioarchaeology of Children: Perspectives from Biological and Forensic Anthropology, vol. 50, Cambridge: Cambridge University Press.

Lewis, M. E. (2018), Paleopathology of Children: Identification of Pathological Conditions in the Human Skeletal Remains of Non-Adults, San Diego, CA: Academic Press. https://doi.org/10.1017/CBO9780511542473

Milner, G. R. \& Boldsen, J. L. (2017), 'Life not death: Epidemiology from skeletons,' International Journal of Paleopathology, vol. 17, pp. 26-39. https://doi.org/10.1016/j. ijpp.2017.03.007

Morrone, A.; Tórv, M.; Piombino-Mascali, D.; Malve, M.; Valk, H. \& Oras, E. (2021), 'Hunger, disease, and subtle lesions: Insights into systemic metabolic disease in fetal and perinatal remains from 13th- to 15th-century Tartu, Estonia,' International Journal of Osteoarchaeology, https://www.doi.org/10.1002/oa.2970

Niiniluoto, I. (1999), Critical Scientific Realism, Oxford: Oxford University Press. https://doi.org/10.1111/j.1933-1592.2004.tb00393.x

Ortner, D. J. (2003), Identification of Pathological Conditions in Human Skeletal Remains, 2nd ed., Washington, DC: Academic Press.

Ortner, D. J. (2011), 'Human skeletal paleopathology,' International Journal of Paleopathology, vol. 1, no. 1, pp. 4-11. https://doi.org/10.1016/j.ijpp.2011.01.002 
Psillos, S. (1999), Scientific Realism: How Science Tracks Truth, London: Routledge.

Putnam, H. (1975), Mathematics, Matter and Method, Cambridge: Cambridge University Press.

Reitsema, L. J. \& McIlvaine, B. K. (2014), 'Reconciling 'stress' and 'health' in physical anthropology: What can bioarchaeologists learn from the other subdisciplines?' American Journal of Physical Anthropology, vol. 155, no. 2, pp. 181-185. https:// doi.org/10.1002/ajpa.22596

Roberts, C. A. \& Buikstra, J. E. (2003), The Bioarchaeology of Tuberculosis: A Global Perspective on a Re-emerging Disease, Gainesville, FL: University Press of Florida.

Roberts, C. A. \& Connell, B. (2004), 'Guidance on recording palaeopathology,' in M. Brickley \& J. McKinley (eds.) Guidelines to the Standards for Recording Human Remains, Reading: British Association for Biological Anthropology and Osteoarchaeology and Institute of Field Archaeologists.

Salmon, M. (1993), 'Philosophy of archaeology: Current issues,' Journal of Archaeological Research, vol. 1, no. 4, pp. 323-343. https://doi.org/10.1007/BF01418109

Siek, T. (2013), 'The osteological paradox and issues of interpretation in paleopathology,' Explorations in Anthropology, vol. 12, no. 1, pp. 92-101.

Stanford, K. (2006), Exceeding Our Grasp. Science, History, and the Problem of Unconceived Alternatives, Oxford: Oxford University Press. https://doi.org/10.1093/0195174089.001.0001

Steckel, R. H.; Larsen, C. S.; Sciulli, P. W. \& Walker, P. L. (2005), The Global History of Health Project: Data Collection Codebook, Columbus, OH: Ohio State University.

Temple, D. H. \& Goodman, A. H. (2014), 'Bioarcheology has a 'health' problem: Conceptualizing 'stress' and 'health' in bioarcheological research,' American Journal of Physical Anthropology, vol. 155, no. 2, pp. 186-191. https://doi.org/10.1002/ajpa.22602

Waldron, T. (1994), Counting the Dead: The Epidemiology of Skeletal Populations, Chichester: John Wiley and Sons. https://doi.org/10.2307/2532978

Wood, J. W.; Milner, G. R.; Harpending, H. C.; et al. (1992), 'The osteological paradox: Problems of inferring prehistoric health from skeletal samples,' Current Anthropology, vol. 33, no. 4, pp. 343-370. https://doi.org/10.1086/204084

Wright, L. E. \& Yoder, C. J. (2003), 'Recent progress in bioarchaeology: Approaches to the osteological paradox,' Journal of Archaeological Research, vol. 11, no. 1, pp. 43-70. https://doi.org/10.1023/A:1021200925063

Alessandra Morrone is a PhD student in archaeology at the University of Tartu (Estonia). Alessandra holds a BSc in natural sciences from the University of Milan (Italy), an MA in bioarchaeology, paleopathology and forensic anthropology from the University of Bologna (Italy), and an MSc in forensic 
archaeology and anthropology from Cranfield University (UK). Her research integrates paleopathological data with stable isotope analysis to identify periods of diet-related physiological stress in medieval and early modern Estonian populations. Her research questions include disparities in health and diet between different age and gender groups, differences between urban and rural communities according to the social status, and the effects of famines and epidemics on past Estonian populations. At the moment, she is focusing on the non-adult individuals of these communities. Furthermore, she is taking part in other bioarchaeological side projects in Umbria, Sicily and Egypt. She is currently a member of the University of Tartu Archemy Lab (https://archemy.ee/) and of the 'Health and Disease in Sicily' project (https:// www.researchgate.net/project/Health-and-Disease-in-Sicily).

Lisa Zorzato is a PhD candidate in philosophy of science at the University of Tartu (Estonia). Currently, she is a visiting researcher in the Philosophy Department of the National and Kapodistrian University of Athens (Greece). Her research interest revolves around the debate between realism and antirealism in philosophy of science. At the moment, her main focus lies on questions concerning the nature of scientific explanations, specifically the role of models and analogies in theory change and theory constructions. 